doi: 10.32620/oikit.2019.86.15

УДК 519.6

В. І. Петренко, Ю. М. Толкунова, Л. І. Смирнова

\title{
Автоматизація контролю параметрів електродвигуна
}

\author{
Національний аерокосмічний університет ім. М. Є. Жуковського \\ "Харківський авіаційний інститут»
}

В статті розроблено методику автоматизації контролю технічних характеристик електродвигуна (ЕД). Контроль технічних характеристик полягає у визначенні та оцінці інформації про відхилення фактичних значень від заданих. Особливе місце на всіх етапах виробництва технічної продукції займає контроль якості. Від досконалості контролю якості, його технічного оснащення і організації багато в чому залежить ефективність виробництва в цілому. Автоматизація процедури контролю дозволяє запобігати випуску підприємствами продукції, що не відповідає вимогам стандартів, технічних умов, затвердженим зразкам, проектно-конструкторської та технологічної документації, при цьому виключає помилки, обумовлені людським фрактором, скорочує витрати часу, забезпечує високу вірогідність контролю і знижує вартість виготовлення і обслуговування. В статті запропоновано блок-схему робочого місця для дослідження технічних характеристик електродвигуна та математичну модель для автоматизації процесу контролю параметрів електродвигуна. Процес контролю полягає в порівнянні фактичних параметрів електродвигуна з параметрами його еталонної моделі. Еталонна модель формується на підставі вхідних сигналів і технічних параметрів ланок підсилювача потужності, електродвигуна та датчика кутової швидкості, які відповідають конструкторській документації. За різницевим сигналом вихідного параметра еталонної моделі та контрольованого зразка електродвигуна проводиться процедура відбракування. Електродвигун представлено за допомогою передавальної функції аперіодичної ланки першого порядку. Рух з'єднання «підсилювач потужності електродвигун - датчик кутової швидкості» моделюється диференціальним рівнянням в безперервній та дискретній фрормах. Для реалізації еталонної моделі використовується рівняння стану у дискретній формі, так як усі процедури управління та діагностування в контрольно-випробувальній апаратурі реалізуються цифровими обчислювальними пристроями. Діагностичною ознакою функціонального стану з'єднання є відхилення вихідного параметру контрольованого ЕД від вихідного параметру еталонної моделі. Відхилення від еталонної величини, яке перевищує допуск є непрямою діагностичною ознакою наявності дестабілізуючих параметрів ЕД. Досліджено залежність відхилення вихідного параметру від зміни коефіцієнта перетворення $\kappa_{E Д}$ та сталої часу $T_{\text {ЕД. }}$

Ключові слова: контроль технічних параметрів, електродвигун, автоматизація контролю, передавальна функція, моделювання, математична модель.

\section{Вступ}

Постановка задачі. На всіх етапах виробництва і експлуатації електродвигунів обов'язковою $є$ процедура контролю технічних характеристик на відповідність конструкторській документації. Автоматизація процедури контролю виключає помилки, обумовлені людським фрактором, скорочує часові витрати, забезпечує високу вірогідність контролю і знижує вартість виготовлення і обслуговування [5].

Вже згадана версія процесу автоматизації контролю полягає в порівнянні фактичних параметрів електродвигуна з параметрами його еталонної моделі.

В роботі [1] розглядається використання мікроконтролерних пристроїв для контролю сталої часу електродвигуна. Доробка мікроконтролерного пристрою істотно розширює функціональну повноту і точність роботи пристрою. Автори роботи [2] пропонують введення до мікроконтролерного пристрою 
контролю електромеханічної сталої часу електродвигуна пікового амплітудного детектору, який $€$ інерційним за частотою напруги живлення електродвигуна змінного струму і безінерційним по обвідній вихідного сигналу датчику контролю електродвигуна змінного струму. В даній статті пропонується автоматизувати контроль сталої часу та коефіцієнту перетворення електродвигуна.

Мета роботи. Розробити блок-схему робочого місця та математичну модель для автоматизації процесу контролю електромеханічної сталої часу та коефіцієнту перетворення електродвигуна.

\section{1 Блок-схема робочого місця}

Пропонована схема робочого місця для дослідження електродвигуна представлена на рисунку 1.

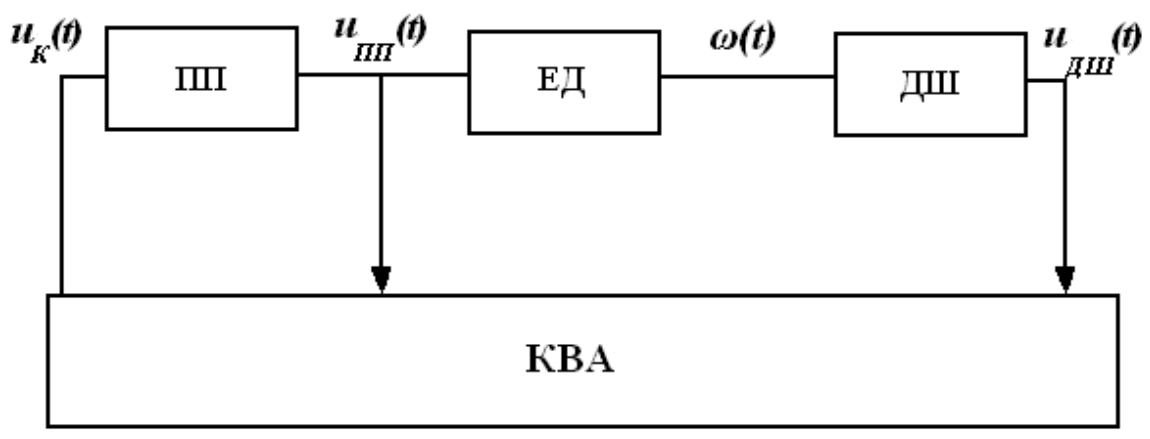

Рис. 1. Блок-схема робочого місця для дослідження електродвигуна

На рисунку 1 представлено:

ПП - регульований підсилювач потужності;

ЕД - електродвигун (об'єкт дослідження);

ДШ - датчик кутової швидкості;

КВА - контрольно-випробувальна апаратура;

$u_{K}(t)$ - керуючий сигнал;

$u_{\Pi \Pi}(t)$ - вихідна напруга підсилювача потужності;

$\omega(t)$ - кутова швидкість ротора ЕД;

$u_{\text {дш }}(t)$ - вихідний сигнал датчика кутової швидкості.

Контрольно-випробувальна апаратура виконує наступні функції:

- фрормує керуючий сигнал,

- контролює вихідні параметри підсилювача потужності, датчика кутової швидкості,

- реалізує еталонну модель послідовного з'єднання ПП - ЕД - ДШ,

- обробляє і документує результати контролю.

\section{2 Математична модель задачі автоматизації}

Еталонна модель фрормується на підставі вхідних сигналів і технічних параметрів ланок ПП, ЕД, ДШ відповідних конструкторській документації. За різницевим сигналом вихідного параметра еталонної моделі та контрольованого зразка ЕД проводиться процедура відбракування. 
У загальному вигляді перетворюючі властивості підсилювача потужності і датчика кутової швидкості відповідають лінійними рівняннями. Рівняння для підсилювача потужності [3]:

$$
u_{\Pi \Pi \Pi}(t)=\kappa_{\Pi \Pi} u_{K}(t),
$$

де $\kappa_{П п}-$ коефіцієнт перетворення ПП.

Рівняння для датчика кутової швидкості [7]:

$$
u_{\text {дш }}(t)=\kappa_{д ш} \omega(t),
$$

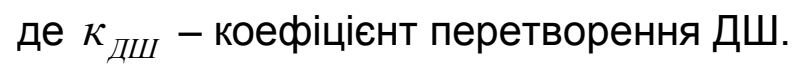

Електродвигун можна представити за допомогою передавальної функції аперіодичної ланки першого порядку [4]

$$
W_{\text {ЕД }}(s)=\frac{\Omega(s)}{U_{\Pi \Pi}(s)}=\frac{\kappa_{\text {ЕД }}}{T_{\text {ЕД }}+1},
$$

де $\Omega(s)$ - кутова швидкість ротора ЕД , $\kappa_{\text {Ед }}-$ коефіцієнт перетворення ДШ, $T_{\text {ЕД }}$ - стала часу електродвигуна.

Послідовне з'єднання ПП-ЕД-ДШ можна представити наступною передавальною функцією

$$
W(s)=\frac{U_{\text {дШ }}(s)}{U_{K}(s)}=\frac{\kappa_{\Pi \Pi} \kappa_{\text {ЕД }} \kappa_{\text {ДШ }}}{T_{\text {ЕД}} s+1} .
$$

Рух з'єднання ПП-ЕД-ДШ моделюється диференціальним рівнянням в безперервній формі:

$$
T_{\text {Ед }} \frac{d u_{\text {ДШ }}(t)}{d t}+u_{\text {дШ }}(t)=u_{K}(t) \kappa_{\Pi \Pi} \kappa_{\text {ЕД }} \kappa_{\text {ДШ }} \cdot
$$

Дискретна форма запису цього рівняння

$$
u_{\text {дш }}(k+1)-\left(1-\frac{T_{0}}{T_{\text {ЕД }}}\right) u_{\text {ДШ }}(k)=u_{K}(t) \kappa_{\Pi \Pi} \kappa_{\text {ЕД }} \kappa_{\text {ДШ }},
$$

де $T_{0}$ - період квантування [6].

Стан з'єднання в будь-якій точці $t=k T_{0}$ часового інтервалу діагностування відображається рівнянням стану як в безперервній формі

так і в дискретній фрормі

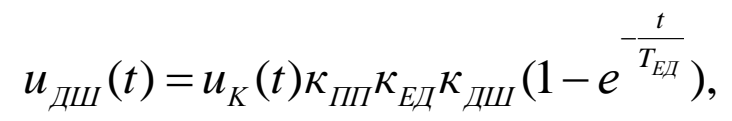

$$
u_{\text {Дш }}(k+1)=\left(1-\frac{T_{0}}{T_{\text {ЕД }}}\right) u_{\text {дС }}(k)+\frac{T_{0}}{T_{\text {ЕД }}} u_{K}(k) \kappa_{\Pi \Pi} \kappa_{\text {ЕД }} \kappa_{\text {Дш }} \cdot
$$

Для реалізації еталонної моделі зручно використовувати рівняння стану у дискретній формі, так як усі процедури управління та діагностування в КВА реалізуються цифровими обчислювальними пристроями.

\section{3 Діагностування функціонального стану електродвигуна}

Процедура діагностування може бути представлена послідовністю наступних операцій:

відтворення еталонної поведінки змінних ЕД, що контролюються; 
- $\quad$ порівняння контрольованих змінних ЕД з еталонними;

- обробка та документування результатів порівняння.

Діагностичною ознакою функціонального стану з'єднання $є$ відхилення:

$$
\square u_{д ш}(k+1)=\hat{u}_{д ш}(k+1)-\tilde{u}_{д ш}(k+1),
$$

де $\hat{u}_{\text {дш }}(k+1)$ - вихідний параметр еталонної моделі; $\tilde{u}_{д ш ~}(k+1)-$ вихідний параметр контрольованого ЕД.

Відхилення $\square u_{\text {дш }}(k+1)$ від еталонної величини, яке перевищує допуск $\delta_{0} \in$ непрямою діагностичною ознакою наявності дестабілізуючих параметрів ЕД.

Відхилення $\left|\square u_{\text {дш }}(k+1)\right| \geq \delta_{0}$ може бути слідством:

- зміни коефіцієнта перетворення $\kappa_{\text {ЕД }}$,

- збільшення сталої часу $T_{\text {Ед }}$;

- збільшення коефіцієнта сухого тертя у підшипниках;

- зменшення обертального моменту.

При виконанні процедури діагностування припускається, що параметри ПП та ДШ відповідають паспортним величинам.

Ідентифікація виду дестабілізуючого параметру визначається прямими діагностичними ознаками.

Наявність відхилення $\kappa_{E д ~}$ від паспортних значень отримується рішенням рівняння

$$
\begin{aligned}
& \square u_{\text {дШ }}(t)=\hat{u}_{\text {дш }}(t)-\tilde{u}_{\text {дШ }}(t)=\hat{u}_{\text {ПII }}(t) \hat{\kappa}_{\text {Ед }} \hat{\kappa}_{\text {дШ }}\left(1-e^{-\frac{t}{\hat{T}_{\text {ЕД }}}}\right)- \\
& -\hat{u}_{\text {III }}(t) \tilde{\kappa}_{\text {ЕД }} \hat{\kappa}_{\text {дШI }}\left(1-e^{-\frac{t}{\hat{T}_{\text {ЕД }}}}\right)=\hat{u}_{\text {III }}(t) \hat{\kappa}_{\text {дाI }}\left(1-e^{-\frac{t}{\hat{T}_{\text {EД }}}}\right) \square \kappa_{\text {EД }} .
\end{aligned}
$$

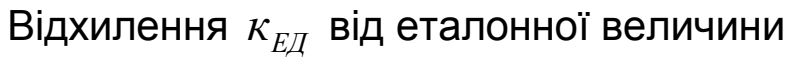

$$
\square \kappa_{\text {ЕД }}=\frac{\square u_{\text {ДШ }}(t)}{\hat{u}_{\Pi \text { II }}(t) \hat{\kappa}_{\text {дШ }}\left(1-e^{-\frac{t}{\hat{T}_{\text {ЕД }}}}\right)} .
$$

3 перехідної характеристики еталонної моделі

$$
\left(1-e^{-\frac{t}{\hat{T}_{\text {ЕД }}}}\right)=\frac{\hat{u}_{\text {дШ }}(t)}{\hat{u}_{\text {III }}(t) \hat{\kappa}_{\text {ЕД }} \hat{\kappa}_{\text {дШ }}} .
$$

Тоді відхилення коефіцієнта перетворення ЕД від еталонної величини визначається виразом

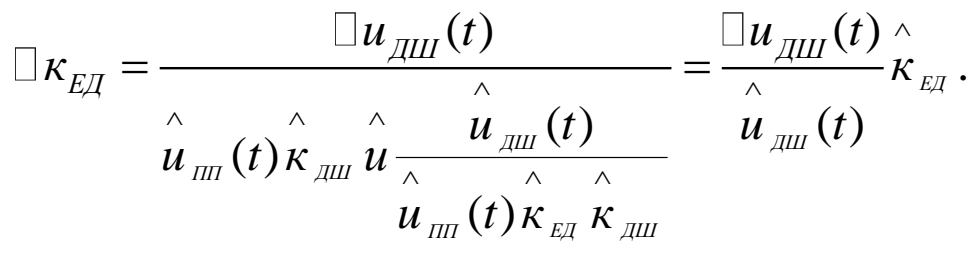


Наявність та величина відхилення сталої часу ЕД також визначається перехідними характеристиками еталонної моделі та ЕД, що діагностується.

3 перехідної характеристики еталонної моделі

$$
\begin{gathered}
\hat{u}_{\text {дш }}(t)=\hat{u}_{\text {ПII }}(t) \hat{\kappa}_{\text {ЕД }} \hat{\kappa}_{\text {дШ }}\left(1-e^{-\frac{t}{\hat{T}_{\text {ЕД }}}}\right), \\
1-\frac{\hat{u}_{\text {дш }}(t)}{\hat{u}_{\text {III }}(t) \hat{\kappa}_{\text {Ед }} \hat{\kappa}_{\text {дШ }}}=e^{-\frac{t}{\hat{T}_{\text {ЕД }}}} .
\end{gathered}
$$

3 перехідної характеристики ЕД, що контролюється

$$
1-\frac{\tilde{u}_{\text {ДШ }}(t)}{\hat{u}_{\Pi \Pi}(t) \hat{\kappa}_{\text {ЕД }} \hat{\kappa}_{\text {дШ }}}=e^{-\frac{t}{\tilde{T}_{\text {ЕД }}}}
$$

В результаті логарифмування система рівнянь приймає вигляд

$$
\left\{\begin{array}{c}
-\frac{t}{\hat{T}_{E Д}}=\ln \left(1-\frac{\hat{u}_{\text {дШ }}(t)}{\hat{u}_{\Pi I I}(t) \hat{\kappa}_{E Д} \hat{\kappa}_{\text {дШ }}}\right), \\
-\frac{t}{\tilde{T}_{\text {ЕД }}}=\ln \left(1-\frac{\tilde{u}_{\text {ДШ }}(t)}{\hat{u}_{\Pi I I}(t) \hat{\kappa}_{\text {ЕД }} \hat{\kappa}_{\text {дШ }}}\right) .
\end{array}\right.
$$

Поділивши почлено ліву та праву частини першого рівняння на друге отримаємо значення дестабілізуючої величини сталої часу ЕД:

$$
\tilde{T}_{\text {Ед }}=\hat{T}_{\text {ЕД }} \frac{\ln \left(1-\frac{\hat{u}_{\text {дш }}(t)}{\hat{u}_{\Pi I I}(t) \hat{\kappa}_{E Д} \hat{\kappa}_{\text {дш }}}\right)}{\ln \left(1-\frac{\tilde{u}_{\text {ДШ }}(t)}{\hat{u}_{\Pi I I}(t) \hat{\kappa}_{\text {Ед }} \hat{\kappa}_{\text {дш }}}\right)} .
$$

Тоді фактична зміна величини дестабілізації сталої часу ЕД має вигляд

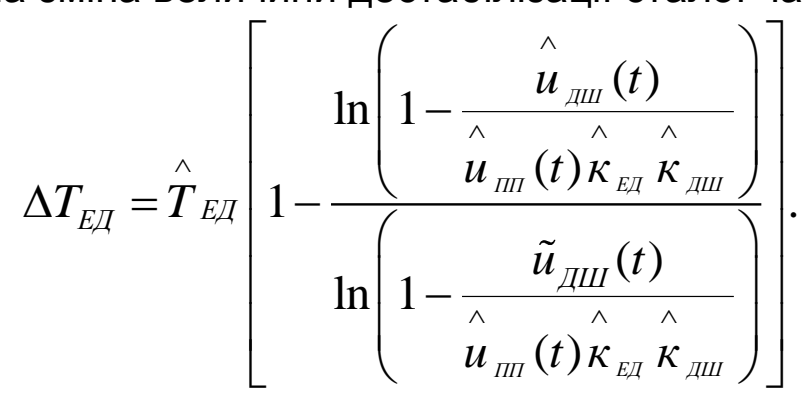

Якщо один з параметрів $\kappa_{E д}$ або $T_{E Д}$ перевищує допустиме відхилення, то такий ЕД підлягає відбракуванню.

\section{Висновки}

В статті розроблено блок-схему робочого місця та математичну модель для автоматизації процесу контролю електромеханічної сталої часу та 
коефіцієнта перетворення електродвигуна. Процес контролю полягає в порівнянні фрактичних параметрів електродвигуна з параметрами його еталонної моделі. За різницевим сигналом вихідного параметра еталонної моделі та контрольованого зразка електродвигуна проводиться відбраковна процедура. Діагностичною ознакою функціонального стану з'єднання є відхилення $\square u_{\text {дш }}(k+1)$ вихідного параметру еталонної моделі від вихідного параметру контрольованого ЕД. Запропонована методика автоматизації процедури контролю дозволяє запобігати випуску підприємствами продукції, що не відповідає вимогам проектно-конструкторської документації, при цьому виключає помилки, обумовлені людським фрактором та скорочує вартість та строки виготовлення і обслуговування.

\section{Список літератури}

1. Анкудинов, К. А. Микроконтроллерное устройство встроенного контроля постоянной времени электродвигателя и мертвого хода механической передачи электропривода постоянного тока [Электронный ресурс] / К. А. Анкудинов // Международный журнал прикладных и фундаментальных исследований. - 2014. - № 8-2. - С. 72-76. - Режим доступу: https://appliedresearch.ru/pdf/2014/8-2/5586.pdf. - 11.10.2019.

2. Анкудинов, К. А. Встроенный контроллер электромеханической постоянной времени электродвигателя и мертвого хода механической передачи электропривода по времени экстремума реакции [Электронный ресурс] / К. А. Анкудинов, Е. Б. Карпов, И. Е. Карпов // Современные наукоемкие технологии. 2014. - № 12 (часть 1) - С. 10-15. - Режим доступу: https://www.toptechnologies.ru/pdf/2014/12-1/34800.pdf. - 15.10.2019.

3. Кулик, А.С. Элементы теории рационального управления [Текст] / А. С. Кулик. - Х.: Нац. аэрокосм. ун-т им. Н.Е. Жуковского «ХАИ», 2016. - 255 с.

4. Кориков, А. М. Основы теории управления [Текст] / А. М. Кориков Томск: Изд-во НТЛ, 2002. - 393 с.

5. Никифоров, А. Д. Управление качеством [Текст] / А. Д. Никифоров - М.: Дрофра, 2004. - 720 c.

6. Бесекерский, В. А. Теория систем автоматического управления [Текст] / В. А. Бесекерский, Е. П. Попов. - М.: Наука, 2003. - 752 с.

7. Dorf, Richard C. Modern Control Systems, $13^{\text {th }}$ Edition [Text] / Richard C. Dorf, Robert H. Bishop. - Prentice Hall, 2017. - p. 1032.

\section{References}

1. Ankudinov, K. A. Mikrokontrollernoe ustrojstvo vstroennogo kontrolja postojannoj vremeni elektrodvigatelja i mertvogo xoda mexanicheskoj peredachi elektroprivoda postojannogo toka [Microcontroller device of built-in control of electric motor time constant and the mechanical transmission of dc electric drive backslash]. Mezhdunarodnyj zhurnal prikladnyh i fundamental'nyh issledovanij, - 2014, no. 8-2, pp. 72-76. Available at: https://applied-research.ru/pdf/2014/8-2/5586.pdf (accessed 11.10.2019).

2. Ankudinov, K. A., Karpov, E. B., Karpov, I. E. Vstroennyj kontroller elektromehanicheskoj postojannoj vremeni elektrodvigatelja i mertvogo xoda mexanicheskoj peredachi elektroprivoda po vremeni ekstremuma reakcii [The built-in controller of electric motor's electromechanical time constant and backlash of electric 
drive mechanical transmission by the time of reaction extremum]. Sovremennye naukoemkie texnologii, 2014, no. 12 (part 1), pp. 10-15. Available at: https://www.toptechnologies.ru/pdf/2014/12-1/34800.pdf. (accessed 15.10.2019).

3. Kulik, A. S. Elementy teorii racional'nogo upravleniya [Elements of rational control theory]. Kharkiv, Nacz. aerokosm. un-t im. M. E. Zhukovs kogo «KhAl», 2016. p. 255.

4. Korikov, A. M. Osnovy teorii upravleniya [Fundamentals of control theory]. Tomsk, NTL, 2002. p. 393.

5. Nikiforov, A. D. Upravlenie kachestvom [Quality control]. Moscow, Drofa, 2004. p. 720.

6. Besekerskij, V. A. Teoriya sistem avtomaticheskogo upravleniya [Theory of Automatic Control Systems]. Moscow, Nauka, 2003. p. 752.

7. Dorf, Richard C., Bishop, Robert H. Modern Control Systems, $13^{\text {th }}$ Edition, Prentice Hall, 2017, p. 1032.

Поступила в редакцию 11.11.2019, розглянута на редколегії 14.11.2019

\section{Автоматизация контроля параметров электродвигателя}

В статье разработана методика автоматизации контроля технических характеристик электродвигателя ЭД. Контроль технических характеристик заключается в определении и оценке информации об отклонении фрактических значений от заданных. Особое место на всех этапах производства технической продукции занимает контроль качества. От совершенства контроля качества, его технического оснащения и организации во многом зависит эфффективность производства в целом. Автоматизация процедуры контроля позволяет предотвращать выпуск предприятиями продукции, не соответствующей требованиям стандартов, технических условий, утвержденным образцам, проектно-конструкторской и технологической документации, при этом исключает ошибки, обусловленные человеческим фрактором, сокращает затраты времени, обеспечивает высокую достоверность контроля и снижает стоимость изготовления и обслуживания. В статье предложена блок-схема рабочего места для исследования технических характеристик электродвигателя и математическая модель для автоматизации процесса контроля электродвигателя. Процесс контроля состоит в сравнении фрактических параметров электродвигателя c параметрами его эталонной модели. Эталонная модель формируется на основании входных сигналов и технических параметров звеньев усилителя мощности, электродвигателя и датчика угловой скорости соответствующих конструкторской документации. По разностным сигналом выходного параметра эталонной модели и контролируемого образца электродвигателя проводится отбраковочная процедура. Электродвигатель представлен с помощью передаточной функции апериодического звена первого порядка. Движение соединения «усилитель мощности - электродвигатель датчик угловой скорости» моделируется дифференциальным уравнением в непрерывной и дискретной формах. Для реализации эталонной модели используется уравнение состояния в дискретной фрорме, так как все процедуры управления и диагностики в контрольно-испытательной аппаратуре реализуются цифровыми вычислительными устройствами. Диагностическим признаком фрункционального состояния соединения является отклонение 
выходного параметра контролируемого ЭД от выходного параметра эталонной модели. Отклонение от эталонной величины, превышающее допуск является косвенным диагностическим признаком наличия дестабилизирующих параметров ЭД. Исследована зависимость отклонения выходного параметра от

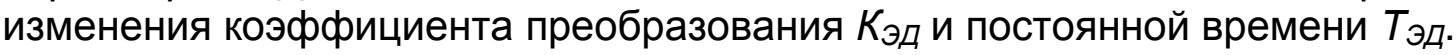

Ключевые слова: контроль технических параметров, электродвигатель, автоматизация контроля, передаточная функция, моделирование, математическая модель.

\section{Automation of Motor Parameter Control}

The technique of the motor control technical characteristics automation is developed in the article. The control of the technical characteristics is to determine and evaluate information on deviation of the actual values from the specified ones. Quality control occupies a special place at all stages of technical products production. Efficiency of production as a whole depends on perfection of quality control, its technical equipment and organization. Automation of the control procedure allows to prevent the production of products that do not meet the requirements of standards, specifications, approved samples, design and technological documentation, while eliminating errors caused by human factors, reduces time costs, provides high reliability of control and reduces the cost of manufacturing and maintenance. The article offers a diagram of the workplace for the study of the motor technical characteristics and a mathematical model for the motor control process automation. The process of control is to compare the actual parameters of the electric motor with the parameters of its reference model. The reference model is formed on the basis of the input signals and technical parameters of the power amplifier units, the electric motor and the angular velocity sensor corresponding to the design documentation. On the difference signals of the output parameter of the reference model and the controlled sample of the motor, a rejection procedure is performed. The electric motor is represented by the first-order aperiodic link transfer function. The motion of the connection "power amplifier - motor angular velocity sensor" is modeled by a differential equation in continuous and discrete forms. For the implementation of the reference model, the equation of state is used in a discrete form, as all the control and diagnostic procedures in the test equipment are implemented by digital computing devices. The diagnostic feature of the connection functional state is the deviation of the output parameter of the controlled motor from the output parameter of the reference model. Deviation from the reference value in excess of the tolerance is an indirect diagnostic sign of the presence of destabilizing parameters of motor. The dependence of the deviation of the output parameter on the change of the coefficient of transformation $K_{E M}$ and the time constant $T_{E M}$ is investigated.

Keywords: control of technical parameters, motor, automation of control, transfer function, modeling, mathematical model.

\section{Відомості про авторів:}

Петренко Василь Іванович - провідний інженер кафедри Систем управління літальними апаратами, Національний аерокосмічний університет ім. М.Є. Жуковського «Харківський авіаційний інститут», Харків, Україна. 
Толкунова Юлія Миколаївна - к.т.н., доцент кафедри Систем управління літальними апаратами, Національний аерокосмічний університет ім. М.Є. Жуковського «Харківський авіаційний інститут», Харків, Україна, y.tolkunova@khai.edu, ORCID 0000-0003-1081-9709.

Смирнова Людмила Іванівна - старший викладач кафедри Систем управління літальними апаратами, Національний аерокосмічний університет ім. М.Є. Жуковського «Харківський авіаційний інститут», Харків, Україна, Smirnovalusi@gmail.com.

\section{About the Authors:}

Petrenko Vasylij - Leading engineer, Department of Aircraft Control Systems, National Aerospace University, M. Ye. Zhukovsky "Kharkiv Aviation Institute", Kharkiv, Ukraine.

Tolkunova Yulija - Ph.D, Associate Professor, Department of Aircraft Control Systems, National Aerospace University, M. Ye. Zhukovsky "Kharkiv Aviation Institute", Kharkiv, Ukraine, y.tolkunova@khai.edu, ORCID 0000-0003-1081-9709.

Smirnova Ludmila - senior teacher, Department of Aircraft Control Systems, National Aerospace University, M. Ye. Zhukovsky "Kharkiv Aviation Institute", Kharkiv, Ukraine, Smirnovalusi@gmail.com. 